\title{
Education, Technology and Technical Images
}

\author{
Prof. Thomas Hauer, Ph.D. \\ VSB - Technical University of Ostrava \\ Department of Social Sciences \\ 17. listopadu $15 / 2172$ \\ 70833 Ostrava - Poruba \\ Czech Republic \\ tomas.hauer@vsb.cz
}

\begin{abstract}
Today man is constantly exposed to attacks of two dominant forces of the contemporary world, which organize and structure its logistic of perception: speed and technical images. The term technical image (according to the media theorist Vilém Flusser, its first form was photography, and the last form by now have been images projected in all possible forms of screens, monitors and displays, including holograms) can be understood as a term referring to the beginning of a new age, which is coming after the age of linear writing. Media theorist Vilém Flusser states in his key texts, that technical images become a dominant cognitive metaphor of the contemporary society. New social culture is being formed in connection with their creation, distribution, transfer and consumption. Such new social structure needs new criteria of analysis; it requires a new interpretive beginning. The following text briefly analyses the dominant cognitive metaphor of Flusser's theory - the concept technical image and its relationship to its outside. In this context, Flusser's inquiry can be seen as a contribution to the analysis - of methodological foundations of educational phenomena at current levels, the possibilities and limits of human knowledge and its transmission in the era of digital teletopy, i.e. in an environment where "to be" means to be connected to the network. This is the context that could be very challenging and inspiring for the current theory of education. Flusser tries to draw attention of teaching sciences to several important phenomena that should be taken into account.
\end{abstract}

Keywords-technical images, apparatus, technology, linear texts, programs, teletopy, educational process

\section{INTRODUCTION: TECHNOLOGY AND TECHNICAL IMAGES}

Technical images are meaningful surfaces. Created by programs, they are dependent on the laws of technology and the natural sciences. They do not represent objects; instead, they represent texts, such as ideologies or scientific laws. In the category of technical images, we find photography, film, video, computer graphics, holography, and virtual reality. The new types of images are best called "techno-images," and the convention they are based on is best called "techno-imagination. No doubt techno-images are a sort of image, and they therefore mean, like every image, a world of myth and of magic. But life in the threatening future will be mythical, magic, in a sense quite different from prehistoric myth and magic. This difference may be stated as follows: prehistoric images mean the world, posthistoric ones mean texts; prehistoric imagination tries to seize the world and posthistoric imagination tries to be text illustration. Therefore, prehistoric myths mean "real" situations and posthistoric myths will mean textual prescriptions, and prehistoric magic is meant to propitiate the world, whereas posthistoric magic will be meant to manipulate people.

In his outstanding study the ontology of the photographic image from 1945, André Bazin, a French film theorist (19181958) expressed his conviction that the primary purpose of art was effort of man to overcome death. Therefore a man began to create the imitation of living beings which reminded him of them. According to Bazin, the oldest works of art are mummies; however, later people used also statues and paintings to resist merciless time [1]. He states that the first scientific and mechanical system of capturing reality emerged in renaissance. It was a perspective whose rules are based on optics and which made it possible to capture reality in a similar way as we perceive through sight. According to him, although modern man no longer believes in the identity of a model and a portrait, true image will enable him to remember it, thus resisting time again. The history of imaging technology is interpreted as evolutional, logical and constant development, chaining invention and events heading for fulfilling human desire for perfect capturing/replicating reality. Each technological innovation - from photography to movement, sound and colour - is a more advanced developmental stage with respect to capturing reality. A. Bazin elaborates his theory in his essay The Myth of Total Cinema. In this essay, he characterizes film as neutral technology, mechanism, which records only in a passive way, and with respect to evolution, it develops so that it could replicate the experience of human perception of reality. André Bazin considers the development of film to be linear chaining of events and invention, each of which is only an enhanced form of the previous one. Innovation is only a formal change closely referring to the previous development. Thus, the myth of the total film is presented as independent driving force controlling the development of film regardless the social, political or economic context. The very centre of Bazin's interest is photography due to its ability - to adjust the shortcomings of the eye, erase the mediator and experience reality. Thus, in his theory of image, André Bazin asserts objectivity as the main quality of mechanical reproduction and its relation to its outside. Therefore, Bazin viewed film technology as a means widening the potential of creators of images, to visualize reality itself more accurately a reliably. "The primacy of the image is both historically and technically accidental. The nostalgia that some still feel for the silent 
screen does not go far enough back into the childhood of the seventh art. The real primitives of the cinema, existing only in the imaginations of a few men of the nineteenth century, are in complete imitation of nature. Every new development added to the cinema must, paradoxically, take it nearer and nearer to its origins. In short, cinema has not yet been invented“ [2].

André Bazin shows how an image of the outside world is formed automatically in photography for the first time, without human creative intervention, in the spirit of strict determinism. All sorts of art are based on the presence of man; only in photography we are granted his absence. It gives us the impression of a "natural" phenomenon, like a flower or a snowflake whose vegetable or earthly origins are an inseparable part of its beauty. This automatic birth has completely reversed the psychology of an image. The objectivity of photography gives it such credibility that cannot be found in any work of art. Despite any objections of our spirit, we have to believe in the existence of the represented object, which is actually made present in time and space. For Bazine, the determinative nature of photography represents a proof of its objective relationship to reality. „Originality in photography as distinct from originality in painting lies in the essentially objective character of photography. For the first time, between the originating object and its reproduction there intervenes only the instrumentality of a nonliving agent. For the first time an image of the world is formed automatically, without the creative intervention of man. Photography affects us like a phenomenon in nature, like a flower or a snowflake whose vegetable or earthly origins are an inseparable part of their beauty“ [3]. Therefore, in general, we expect from photography that in a way it is related to reality. However, what about the contemporary form of technical images and their relationship to their outside?

\section{THEORIES IN PEDAGOGY}

In pedagogy, a large number of different theories of education have been created during its development. Their contents are usually reflections on the aims of education, the role of teachers, the status of pupils or students on the content of the different subjects and the importance of socio-cultural education. With respect to a conceptual focus and philosophical bases, it is possible to identify seven major streams that can be traced in contemporary theories of education. They are spiritualistic theories, personalistic theories, cognitive and psychological theories, technological theories, socio-cognitive theories, social theories, and academic theories. The representatives of spiritualistic theories of education [5] are interested in the relationship between the human self and the universe from the metaphysical point of view. The subject of this approach to education is not an individual as such, but an individual as a part of the universe. Thus, the focus of education is not the development of the subject, but rather the relationships of the individual as a part of a larger whole. The core of spiritual knowledge consists in the subject's transcendence, the relationship to the divine, to the mystical reality. This kind of pedagogy is based on a non-authoritative relation to the pupil, which is reflected in the content, methodological and organizational dimensions of teaching. Theories accentuating the individual's autonomy and freedom are reflected in the anti-authoritarian forms of education. These concepts are still topical and come in many forms, such as free education (A. S. Neill), a non-directivity (C. R. Rogers), open education (A. Paré).

Cognitive and psychological theories emphasize the learning processes and the status of the pupil's existing knowledge. The teacher should know the level of knowledge which the pupil already has, the pupil's ways (styles) of learning and processing information, the level of his or her understanding. Acquiring knowledge is the result of the pupil's own cognitive activity, when the pupil confronts new information with the existing mobilized knowledge, and creates a new context and meaning. It is also important for the learners to develop knowledge of their own cognitive processes and reflect on their own cognitive approaches and mechanisms of knowledge acquisition. Socio-cognitive theories represent a wide area of educational theories that emphasize the social and cultural dimensions of the educational process. They demonstrate and illustrate the importance of a large number of social factors that have an important role in teaching, such as the influence of classmates, the influence of teacher's personality, the pupil's self-conception, his relationship to his parents and to the society, his cultural background and social factors that may influence his relationship to education. Social theories of education understand education as a tool for transformation of society. The goal of education is to build a new society whose characteristics will be a higher degree of social, cultural and economic responsibility [7].

Generally, they are based on the conviction that the contemporary world is in deep crisis. The crisis of values and the environment increasingly affects our everyday culture, whose development does reflect a view of ensuring our survival on the Earth. Different technologies are evolving faster than the understanding of the objectives for which they should be used, and therefore it is necessary to take control over the development and change the social, cultural and ecological fabric of the society. These theories raise questions whether education can shape the learners to acquire critical thinking, to be skilful workers and active citizens, or whether education can promote democracy and equitably serve all learners. These theories have several mutually different currents and different theoretical bases. Technological theories emphasize [6] the formal aspect of teaching and consider the improvement of teaching methods, including the use of new technological resources the main way to achieve progress in education. Technological theories particularly emphasize logical arrangement of aids for the organization of teaching, and they give them preference over the content of education. Their emphasis is on the planning and organization of educational processes, on using modern communication technologies.

The fundamental problem, and at the same time, the weakness in the theories briefly characterized above is the fact that it is very difficult for them to cope with two new phenomena, both methodologically, and within the theory itself - the phenomena that newly structure logistics of perception and acquisition of knowledge and findings in the educational process - with teletopy [4] and technical images. Flusser's theory and research helps us understand the boundaries and 
limitations of current theories, as well as the challenges with which Flusser confronts them.

\section{PUTting REALity TOGETHER}

The term technical image (according to the media theorist Vilém Flusser, its first form was photography, and the last form by now have been images projected in all possible forms of screens, monitors and displays, including holograms) can be understood as a term referring to the beginning of a new age, which is coming after the age of linear writing. Historically as well as ontologically, compared to the previous tradition, these technical images mean rupture, a breakthrough. Creating technical images was the necessary consequence of the link of texts to sensuously perceptible reality from which texts were abstracted earlier. Technical images have been an item of philosophers' interest since the time when W. Benjamin, a German cultural critic published the essay Das Kunstwerk im Zeitalter seiner technischen Reproduzierbarkeit (The Work of Art in the Age of Mechanical Reproduction, 1936), [15] which is now commonly known. Unlike W. Benjamin, who focused on the theory of social and aesthetic issue of the original work and its copy in the age of serial reproducibility, Flusser concentrated on the technology of reproducibility of any work in the environment of so called new media which were just emerging. Just as Benjamin, Flusser recognized the first technically reproducible work in photography, however, unlike him (or the photography theorists such as - A. Bazin. S. Sontag, či S. Kracauer), he used his analysis as a tool of prediction of the future society development

At the beginning of Flusser's philosophy of technical images, we encounter a cultural-sociological model where the author in five stages indicates the changes in relationship between man and the world, depending of the kind of the medium dominant for the particular historical epoch. This model is a ladder with five rungs. The mankind has climbed this ladder step by step - from the concrete to higher and higher abstractions. It is a model of cultural history and the alienation of man from the concrete experience of reality, a model in which man puts agents/tools - an image, text, technical image - between himself and the world.

First rung: Animals and "primitive” people are immersed in an animate world, a four-dimensional space-time continuum of animals and primitive peoples. It is the level of concrete experience.

- Second rung: The kinds of human beings that preceded us (approximately two million to forty thousand years ago) stood as subjects facing an objective situation, a three-dimensional situation comprising graspable objects. This is the level of grasping and shaping, characterized by objects such as stone blades and carved figures.

- Third rung: Homo sapiens sapiens slipped into an imaginary, two-dimensional mediation zone between itself and its environ $\neg$ ment. This is the level of observation and imagining character-ized by traditional pictures such as cave paintings.

- Fourth rung: About four thousand years ago, another mediation zone, that of linear texts, was introduced between human beings and their images, a zone to which human beings henceforth owe most of their insights. This is the level of understanding and explanation, the historical level. Linear texts, such as Homer and the Bible, are at this level.

- Fifth rung: Texts have recently shown themselves to be inacces $\neg$ sible. They don’t permit any further pictorial mediation. They have become unclear. They collapse into particles that must be gathered up. This is the level of calculation and computation, the level of technical images. [8]

Linear texts thus occupied a dominant position as a carrier of vital information only for about four thousand years. It is the only time when we can speak of "history" in the strict sense. In the existence of mankind, linear texts played only a transitional role, in this sense, "history" was only an interlude, an episode. The difference between traditional and technical images, then, would be this: the first are observations of objects, the second com $\neg$ putations of concepts. The first arise through depiction, the second through a peculiar hallucinatory power that has lost its faith in rules. This essay will discuss that hallucinatory power. First, however, imagination must be excluded from the discussion to avoid any confusion between traditional and technical images. Flusser's model then describes a line - an image, text, technical image -, while a traditional and technical image quantitatively differ. In the following part of the text, we will show this principal dissimilarity. Traditional images (such as cave paintings in Lascaux) are abstractions of the first order, if they abstract from the concrete world, while technical images are abstractions of the third order, they abstract from texts which abstract from traditional images which abstract from the concrete world. The last part of this sentence is important, because it suggests that in the case of technical images (from a photograph to a computer image), we deal with abstractions of the third order, not with images in the usual sense. Technical images make it possible to handle phenomena so that they can be perceived according to the apparatus programme or the intention of the apparatus user. Neither texts nor traditional images "can" do this. The new possibility to provide virtual, fundamentally cybernetic environment for our everydayness has become a reality. This is what Flusser conveys us in his philosophy of technical images with the urgency of his own. Technical images furnish the space of our everydayness in a similar way as an architect furnishes a room with new furniture [9]. Technical images work by supplying a reality where it is needed A neutral pile of points, a calculable pile, which must be "put together so that the world could be grasped, imagined, understood again the consciousness could become consciousness of itself again" is the subject of formation into technical images. "The world in which they find them $\neg$ selves can no longer be counted and explained: it has disintegrated into particles-photons, quanta, electromagnetic particles. It has become intangible, inconceivable, incomprehensible, a mass that can be calculated. Even their own consciousness, their thoughts, desires, and values, have disintegrated into particles, into bits of information, a mass that can be calculated" [10]. And this is what technical images are used for - putting reality together again. Our new arrangement of the world, new after the end of the age of linear writing, depends on two things - on apparatuses and on their programmes. 


\section{EDUCATION AND DECODING OF TECHNICAL IMAGES}

Technical image as an abstraction of the third order shows two qualities which differentiate it from abstractions of the first order (images) as well as from abstractions of the second order (texts). The technical image is an image produced by apparatuses. „The technical image is an image produced by apparatuses. As apparatuses themselves are the products of applied scientific texts, in the case of technical images one is dealing with the indirect products of scientific texts. This gives them, historically and ontologically, a position that is different from that of traditional images. Historically, traditional images precede texts by millennia and technical ones follow on after very advanced texts. Ontologically, traditional images are abstractions of the first order insofar as they abstract from the concrete world while technical images are abstractions of the third order: They abstract from texts which abstract from traditional images which themselves abstract from the concrete world. Historically, traditional images are prehistoric and technical ones 'post-historic' (in the sense of the previous essay). Ontologically, traditional images signify phenomena whereas technical images signify concepts. Decoding technical images consequently means to read off their actual status from them" [11]. The affirmation that the technical image is, after all, created by man, is defensible only in this context. Man creates it, but only to the extent enabled by the apparatus programme. It is about two things: the apparatus and the apparatus programme. Both the apparatus and the programme are established in texts - scientific texts. The apparatus can only be produced according to scientific texts; the same is true about the apparatus programme [12]. Scientific texts are basically complex concepts. And therein lies the key difference between traditional and technical images. The difference between traditional and technical images, then, would be this: the first are observations of objects, the second com $\neg$ putations of concepts. Simply speaking, the technical image is, in fact, a visualized concept. Cameras as well as a photograph are the result of a complicated scientific institution, a computer, a monitor; a display, etc. are the results of a very complicated instruction conveyed by scientific concepts. Apparatuses, like the means for creating technical images, need functionariescreators of fictions. This reverses the original relation "man/apparatus" and man works as a function of apparatuses. He orders apparatuses what the apparatuses themselves ordered him. Around these transmission points sit functionaries who press the keys of apparatuses, especially those that compute images. For these images model the behavior, perception, and experience of all other functionaries. The functionaries instruct the images about how the images should instruct the receivers. The apparatuses instruct the functionaries how they are to instruct the images. And other apparatuses instruct these apparatuses about how the functionaries are to instruct.

Creating technical images was the necessary consequence of the link of texts to sensuously perceptible reality from which texts were abstracted. The development of science in the twentieth century drew an abstract concept from an illustrative idea in an unexpected way. However, if two texts become incomprehensible, there is nothing more to explain. And right during this big crisis of texts, technical images were invented in order to make texts comprehensible again. During this crisis of texts, technical images were invented: in order to make texts comprehensible again, to put them under a magie spell - to overcome the crisis of history. The order in the contemporary society is created by technical images which work in a different way than the traditional images and require a new way of acquiring and handling. What is an image for Flusser? For Flusser, images are surfaces with a meaning. They refer to something in space-time continuum "outside over there ", something they are supposed to make comprehensible for us as abstractions (as abbreviations of four dimensions of space-time continuum into two dimensions of a surface). Flusser uses the term imagination for this specific ability to abstract surfaces from space-time continuum and to project them into space-time continuum again. Therefore, images work by mediating the relationship between the world and man. Man "exists", it means that the world is not immediately accessible for him, therefore the function of images is to mediate the world for man. However, whenever they do this, they put themselves "between" the world and man. Images were supposed to be maps, but they become obstacles. Instead of presenting the world, they obscure it and man finally begins to live in the function of images he himself created. He stops decoding images and he projects them undecoded to the world "outside over there". The principal consequence of this is the fact that the world suddenly appears to be a complex of images, factual configurations. Flusser calls this reversing of the function of an image "idolatry" (idiolatry) and describes how it takes place. The technical images currently all around us are in the process of magically restructuring our 'reality' and turning it into a 'globál image scenario'. Essentially this is a question of 'amnesia'. Human beings forget they created the images in order to orientate themselves in the world. Since they are no longer able to decode them, their lives become a function of their own images: Imagination has turned into hallucination.

What do technical images mean, if they are not pictures in the usual sense? They are models. They are models that give form to a world and a consciousness that has disintegrated; they are meant to "inform" that world. Their vector of signi $\neg$ fication is therefore the reverse of that of earlier images: they don't receive their meaning from outside but rather project meaning outward. They lend meaning to the absurd. Some technical images fulfil the vision, according to which reality could be fundamentally taken apart into points and then assign a concept to each point. „Apparatuses incorporate the 1-0 structure because they simulate the structure of our nervous system. There, too, we are dealing with a mechanical (and chemical) turning on and off of streams of electrons between the nerve synapses. From this standpoint, digital codes are a method -the first since human beings began to codify- of giving meaning to quantum leaps in the brain from the outside. We are faced with a self-concealing loop. The brain is an apparatus that lends meaning to the quantum leaps that occur in it, and now it is about to turn this meaning-giving function over to apparatuses of its own accord, then to reabsorb what they project. So the new codes are digital basically because they are using simulated brains to simulate the meaning-giving function of the brain" [14]. Like traditional images show reality, technical images produce-form reality. Traditional images are mirrors of reality; reality is, on the other hand, a "mirror" of a technical image or scientific concept or scientific text. The image shows one fact; technical images produce so many facts 
as the apparatus programme allows them. Our presence therefore differs from the age of linear writing (the age of text), among other things, by the fact that is characterized by the "inflation of reality" produced by technical images and technical devices. This has significant cognitive consequences because technical images do not represent-show anything of the world (although they pretend that they do so), but project something in it.

What is described by technical images is something thrown from inside to outside. Here we come to the essence of the problem. „What does a technical image mean is an incorrectly formulated question. Although they appear to do so, technical images don't depict anything; they project something. The signified of a technical image, whether it be a photograph of a house or a computer image of a virtual airplane, is something drawn from the inside toward the outside. And it is not out there until it has been drawn out. Therefore technical images must be decoded not from the signifier but from the signified, not from what they show but from what they show for. And the question appropriate to them is, to what end do technical images mean? To decode a technical image is not to decode what it shows but to read how it is programmed. Therefore, a technical image is a tool whose function is - as with any intermediary tools or machines - to change reality. But what is reality? Material tools (a power plant or a car) change material reality. A technical image changes symbolic reality, it changes meanings, but as reality becomes reality only after meanings are assigned to it, a technical picture changes reality itself. Reality ceases to be text for man and becomes an image and image. The world and things "visualized" by a technical image are things created by human intellect, not visualized by it. Technical paintings thus put us into a situation in which our traditional efforts - to represent reality adequately - do not make sense. Reality is "surplus", it is produced by apparatuses and the creators of fiction. Since the beginning of every process of discovering reality is perception, a technical image is able to change the field of perception and force each individual to a particular way of perceiving reality, allows to handle events so that they are perceived according to the apparatus programme or the intent of the person who uses the apparatus. Neither texts nor images "can" do this. Disputes about the importance of reality thus move from the level of abstraction of the second order (texts) to the level of abstraction of the first order (pictures) and abstractions of the third order (technical images) are the means to it. In practice, this "transcript", transfer of line of reasoning from the level of text to the level of a technical image takes place wherever the electronic networks reach. Today, we argue, we recognize we make decisions, assess, etc. not "through" text but "through" images.

\section{CONCLUSION}

The order of the network society - teletopy, is based on technical images that work differently from traditional images and linear writing, thus calling for a new way of acquiring and handling. They reverse the educational processes for a variety of reasons. These reasons relate to the essential foundations of modern education, including university education. A whole new industrial and educational space is organized around information flows, and as a whole, "our society is based on flows. Capital flows, flows of information, flows of technology, flows of organizational interaction, flows of images, sounds and symbols. This creates a new form of social space, which determines the form of the network society. According to these concepts, educational institutions may succeed only if they become network nodes, because the power of flows is gaining a superior position over the flows of power. The presence or absence of a network and the dynamics of each network with others within the network are critical sources of influence and changes in society. Therefore, we call the current form of society - teletopy. At present, the quality of the educational process is more and more linked mainly to dromocratic teletopy, i.e. to the capability, the ability and willingness of the educational process participants to connect to the cyberspace digital networks. The technological progress, rapidly growing in the 21st century, also asserted itself in the ways in which we create, distribute and evaluate knowledge, skills and information today.

\section{REFERENCES}

[1] Bazin, A.: 1967, What is Cinema? tr. H. Gray, Volume I, University of California Press, pp. 9 - 10

[2] Bazin, A.: 1967, What is Cinema? tr. H. Gray, Volume I, University of California Press, pp. $21-22$

[3] Bazin, A.: 1967, What is Cinema? tr. H. Gray, Volume I, University of California Press, p. 13

[4] J. Van Dijk, The network society: Social aspects of new media. London: SAGE., pp 56-59, 2006

[5] Y. Betrtand, Contemporary Theories and Practice in Education, Atwood Pub; 2 edition, pp. 9-28, 2003,

[6] Y. Betrtand, Contemporary Theories and Practice in Education, Atwood Pub; 2 edition, pp. 78, 2003

[7] C. L. David., Learning Theories, A to Z, Oryx Press, Westport, Londra, pp 81-85, 2002

[8] V. Flusser, Into the Universe of Technical Images, University of Minnesota Press, Minneapolis: London 2011, pp. 6 - 7

[9] V. Flusser, Into the Universe of Technical Images, University of Minnesota Press, Minneapolis: London, 2011, p. 31

[10] V. Flusser, Into the Universe of Technical Images, University of Minnesota Press, Minneapolis: London, 2011, p. 31

[11] V. Flusser, Towards a Philosophy of Photography, Reaktion Books, p. 14 2000

[12] A. Finker, R. Guldin, G. Bernardo.:, Vilém Flusser, An Introduction, University of Minnesota Press 2011, p.101

[13] V. Flusser, Towards a Philosophy of Photography, Reaktion Books, p. 13, 2000

[14] Flusser, V.: Writings, University of Minnesota Press, Minneapolis: London: 2002, p. 48.

[15] Benjamin, W.: 1969, The Work of Art in the Age of Mechanical Reproduction,” in Illuminations, ed. Hannah Arendt, trans. Harry Zohn (New York: Schocken), pp. 48-62 